Advance Publication

doi:10.5652/internationaleconomy

ie $2022.25 .01 . \mathrm{kk}$

\title{
Impacts of Protectionism and Political Conflict: Recent Developments ${ }^{\dagger}$
}

\author{
Kozo Kiyota \\ Keio University, RIETI, and TCER
}

\begin{abstract}
With the growing concerns about increasing protectionism, several empirical studies have investigated the effects of protection. While these studies presented interesting and important findings, few of them have discussed their frameworks and results in a comprehensive manner. This paper reviews these recent studies. We first show that they mainly employ either quantitative trade models or difference-in-differences design to investigate protectionism. We then discuss the strengths and limitations of these approaches. Finally, we consider possible directions for future research.
\end{abstract}

Key Words: Protectionism, political conflict, international trade, quantitative trade models, difference-in-differences design, synthetic control method, event study

"Economists disagree about a lot of things, but the superiority of free trade over protection is not controversial” Rodrik (2018, p. 74).

\section{Introduction}

The protectionism movement has become increasingly active in recent years. For example, in 2016, the majority of voters in the United Kingdom voted to leave the European Union (EU) (i.e., Brexit). In 2017, the Trump administration withdrew from the negotiations for the Trans-Pacific Partnership (TPP). In 2018, the United States imposed tariffs on 283 billion dollars of US imports, with rates ranging from 10 to 50 percent (Amiti, Redding, and Weinstein, 2019). In response to these US tariffs, China began by levying tariffs on US exports. In 2019, the Japanese government dropped South Korea (hereafter Korea) from its "white list" of countries that receive preferential treatment for export licensing. The perceived threat to Korea's vital industries led to consumer boycott activities in Korea against purchases of Japanese products and services. Moreover, the COVID-19 pandemic in 2020 has also induced protection. For example, Evenett, Fiorini, Fritz, Hoeckman, Lukaszuk, Rocha, Ruta, Santi, and

Received 8 January 2021, Accepted 17 November 2021, Released online in J-STAGE as advance publication 29 December 2021.

+ This article is based on my invited lecture for the Kojima Kiyoshi Prize in October 2020. The author benefited from helpful comments on earlier drafts from Naoto Jinji, Isao Kamata, Hayato Kato, Fukunari Kimura, Yoshinori Kurokawa, Toshihiro Okubo, Akira Sasahara, Nobuaki Yamashita, and an anonymous referee. He also gratefully acknowledges the financial support of the Japan Society for the Promotion of Science (JSPS) Grants-in-Aid (JP19H00598). The usual disclaimers apply. 
Shingal (2020) found that some countries acted to restrict exports and facilitate imports of medical and food products in response to COVID-19.1)

Given that more than 300 international trade agreements have been recognized as in force by the World Trade Organization, there must be a net benefit to the member countries' standards of living. Therefore, few economists expected these protectionism movements five years ago. Indeed, "only 3 years ago, it would have been rare to have come across a serious observer of the world economy that conjectured the globalization of the world economy - in terms of the proliferation of economic integration agreements and trade-policy liberalisations - had peaked" (Baier, Bergstrand, and Bruno, 2019, p. 3488). One of the main reasons for this is that "after more than a half-century of leading efforts to lower international trade barriers, in 2018 the United States enacted several waves of tariff increases on specific products and countries" (Fajgelbaum, Goldberg, Kennedy, and Khandelwal, 2020, p. 2).

This "return to protection" is unprecedented in the postwar era in the sense that the sizes of the countries involved are large, the magnitudes of the tariff increases are also large, and the breadth of tariffs across sectors is wide. With growing concerns about such increasing protectionism, several studies have investigated the effects of protection. While these studies presented interesting and important findings, to our knowledge few studies have discussed their results in a comprehensive manner. ${ }^{2)}$ Therefore, the similarities and differences of those studies are unclear.

One may argue that several studies have already investigated the effects of trade liberalization. Therefore, the effects of protection could be viewed as simply the opposite of those studies. As argued by Rodrik (2018), the negative effects of protection are obvious for economists. However, many people still support the protection of domestic industries from foreign competition. To facilitate constructive discussion, recent studies are more likely to have emphasized both the economic and statistical significance of globalization. ${ }^{3)}$ Therefore, a detailed analysis of the effects of protection is necessary.

This study reviews the recent developments on the issue of the impact of protection and discusses some directions for future research. In this paper, we focus on empirical studies because our main concern on this issue is the quantitative impacts. The main contribution of this paper is that we examine the various methodologies that have been used to determine the effects of protection. This enables us to identify the advantages and disadvantages of these methodologies.

Note that there are numerous studies on the effects of protectionism and political conflict, such as studies on war and sanctions. ${ }^{4}$ Note also that there are a number of studies that inves-

1) In this connection, Fuchs, Kaplan, Kis-Katos, Schmidt, Turbanisch, and Wang (2021) examined the political and economic factors that facilitated access to Chinese medical equipment (e.g., face masks) during the first two months of the COVID-19 pandemic. They found that both political and economic ties with Chinese provinces increased Chinese exports of medical goods to partner countries.

2) An exception is a very recent study by Fajgelbaum and Khandelwal (2021) that reviewed the studies on the US-China trade war.

3) See Costinot and Rodríquez-Clare (2014) for the importance of the quantification of the consequences of globalization in recent trade studies.

4) For example, Yasuba (1996) found that the Japanese military expansion in the 1930s created an artificial shortage of mineral resources in Japan. Haidar (2017) investigated whether export sanctions against Iran in 2008 led to export deflection to non-sanctioning countries. Tanaka, Ito, and Wakasugi (2019) 
tigate the determinants of protection and political conflict rather than their impacts. For example, Becker, Fetzer, and Novy (2017), Alabrese, Becker, Fetzer, and Novy (2019), Liberini, Oswald, Proto, and Redoano (2019) examined who voted for Brexit, whereas Di Tella and Rodrik (2020) examined which factors shape protectionist preferences in the United States. Because it is unrealistic to cover all of them, we limit our focus to the impacts of three issues that have been of substantial interest in recent studies: Brexit, recent US trade policies, and consumer boycotts. The impacts of the actual war are also beyond the scope of this paper.

The rest of the paper proceeds as follows. The next section briefly describes the methodologies employed in recent studies. Section 3 summarizes the results of recent studies. Section 4 discusses some possible directions for future research.

\section{Methodology}

Recent studies have mainly employed two approaches. ${ }^{5)}$ The first is quantitative trade models, and the second is the difference-in-differences (DID) design. ${ }^{6}$ An advantage of the use of quantitative trade models is that the magnitude of economic impacts can be quantified. Because these models are based on the economic model, they can quantify the impacts on aggregate variables such as welfare and GDP. In contrast, an advantage of the use of a DID design is that is clarifies the causal relationship. Because it is based on a simple econometric framework, it cannot quantify the impacts on welfare. In contrast, because the analysis of a DID design itself is very simple, it can be useful to examine the impacts on disaggregated variables such as price and quantity, although some studies focused on aggregate variables such as employment and GDP.

It is also important to note that, on the one hand, a DID design requires data both before and after the event (i.e., ex ante and ex post data). On the other hand, quantitative trade models are based on data before the event only. This is because the main focus of quantitative trade models is to compute the situation when there is no political conflict (i.e., a counterfactual situation). This section briefly explains these methodologies.

\subsection{Quantitative trade models}

There are two types of quantitative models. The first is partial equilibrium models that focus on the market of a specific product. The second is general equilibrium models that focus on markets of several products and their interactions. There are some important differences between them. First, because general equilibrium models consider several markets and their interactions, they tend to be more complex than partial equilibrium models. Second, while partial equilibrium models clarify the difference of the impacts between consumers and pro-

analyzed the impact of China-Japan conflict in 2012 on employment in Japan. Li, Jian, Tian, and Zhao (2021) examined the impact of China-Japan and China-US conflicts on Chinese imports between 2000 and 2006.

5) Earlier studies employed different approaches. For example, Michaels and Zhi (2010) used gravity models to investigate the effects of the France-US conflict, including year times France country dummies for identification. Davis and Meunier (2011) also employed gravity models to examine the effects of the France-US and China-Japan conflicts by adding a political tension variable.

6) Kehoe, Pujolàs, and Rossbach (2017) present an excellent review of quantitative trade models, although the recent protectionist movement is beyond the scope of their paper. 
ducers, general equilibrium models clarify the difference of the impacts between factors (e.g., labor and capital owner; skilled workers and unskilled workers). Finally, general equilibrium models usually impose market clearing conditions in factor markets while partial equilibrium models do not. This implies that general equilibrium models focus on long-run effects whereas partial equilibrium models focus on short-run effects.

For both model types, the basic approach consists of the following three steps: 1) build a model; 2) estimate the structural parameters of the model; and 3) conduct counterfactual simulations, based on the estimated parameters in step 2. Quantitative models have a long history. Earlier studies on partial equilibrium models include Hufbauer and Elliott (1994) and Sazanami, Urata, and Kawai (1995). Recent studies such as that by Head and Mayer (2019), however, built more complex models in the sense that they incorporate the production network of multinational firms across countries.

Quantitative general equilibrium models are called computable general equilibrium (CGE) models and have been used by policy makers as well as academic researchers. An example is the Global Trade Analysis Project (GTAP) model (Hertel, 1997). The latest version of the GTAP model described in Hertel et al. (2012) has over 13,000 structural parameters (Adao, Costinot, and Donaldson, 2017). In contrast, a more recent CGE model by Eaton and Kortum (2002) requires only one parameter to conduct counterfactual analysis (i.e., the trade elasticity). More specifically, in Eaton and Kortum's (2002) model, the gains from trade, which are defined as the ratio of per capita real income under free trade relative to per capita real income under autarky, is written as:

$$
\begin{aligned}
& \log \left(\frac{\text { Per capita income under free trade }}{\text { Per capita income under autarky }}\right) \\
& =-\frac{1}{\text { Trade elasticity }} \log \left(\frac{\text { Domestic demand }}{\text { Total demand }}\right),
\end{aligned}
$$

where Trade elasticity $>0$. That is, the gains from trade increase as the share of imports and trade elasticity increase. This is because of the strong functional form assumptions. Therefore, more recent studies attempt to relax the strong functional form assumptions without circling back to GTAP's 13,000 parameters. ${ }^{7)}$

On the one hand, quantitative trade models have a strong advantage in counterfactual simulations. Once the models are built and their parameters are estimated, one can examine various policy effects such as trade liberalization or trade protection. On the other hand, one of the limitations of quantitative trade models is that they are sometimes very complex. However, recent quantitative trade models are likely to have fewer structural parameters, generate plausible results, and can be easily replicated by other researchers. Although it is not easy to build such models, the development of new quantitative models would contribute to policy discussions and the academic literature. ${ }^{8)}$

7) For example, although their focus is the effect of trade liberalization rather than that of protection, Adao, Costinot, and Donaldson (2017) proposed an approach to reduce the dimensionality of what is required for counterfactual analysis in a general equilibrium trade model.

8) For the technical aspects of the recent quantitative models, see Ossa (2016). 


\subsection{Difference-in-Differences (DID) designs}

A DID design is another commonly used approach to examine the impacts of protection or political conflict. This methodology is a statistical technique that attempts to mimic an experimental research design using observational study data. A DID design studies the differential effect of a treatment-on-treatment group versus a control group in a natural experiment. This calculates the average differences over time in the outcome variable between the treatment group and the control group.

Denote a member of the group (e.g., country) as $i$ and time as $t$. A standard DID regression takes the following form:

$$
Y_{i t}=\beta_{0}+\beta_{1} D_{i}+\beta_{2} \text { Post }_{t}+\beta_{3}\left(D_{i} \times \text { Post }_{t}\right)+\gamma X_{i t}+\varepsilon_{i t},
$$

where $Y_{i t}$ is the outcome variable; $D_{i}$ is a dummy variable that equals one if a member $i$ belongs to the treatment group and zero otherwise; Post $t_{t}$ is a dummy variable that equals one for all periods after the event and zero otherwise; $X_{i t}$ includes control variables; and $\varepsilon_{i t}$ is an error term. In the context of our analysis, the event includes political conflicts and consumer boycotts.

From this regression, we have:

$\beta_{0}$ : Mean of the observations for $D_{i}=0$ and Post $_{t}=0$;

$\beta_{0}+\beta_{1}$ : Mean of the observations for $D_{i}=1$ and Post $_{t}=0$;

$\beta_{0}+\beta_{2}$ : Mean of the observations for $D_{i}=0$ and Post $_{t}=1$;

$\beta_{0}+\beta_{1}+\beta_{2}+\beta_{3}$ : Mean of the observations for $D_{i}=1$ and Post $_{t}=1$.

Table 1 summarizes this relationship. The coefficient $\beta_{1}$ captures the difference between treatment and control groups before the event, while $\beta_{1}+\beta_{3}$ indicates the difference between them after the event. Therefore, the difference between them, or the coefficient of the interaction term $\beta_{3}$, captures the differential effect of these two differences, which is the reason why this approach is called "difference-in-differences."

A DID design is based on two important assumptions. The first is the exogeneity of the event. If the event is endogenous, we cannot identify the causal effect of the event on the outcome variable. The second is the common (pre-)trend assumption (or parallel trend assumption). Before the event, the trend of the outcome variable should be the same for the treatment and control groups. If this assumption does not hold, it is difficult to determine whether the

Table 1: Interpretation of the Coefficients

\begin{tabular}{cccc}
\hline & $\begin{array}{c}\text { Before the event } \\
\left(\text { Post }_{t}=0\right)\end{array}$ & $\begin{array}{c}\text { After the event } \\
\left(\text { Post }_{t}=1\right)\end{array}$ & Difference \\
\hline $\begin{array}{c}\text { Treatment } \\
\left(D_{i}=1\right)\end{array}$ & $\beta_{0}+\beta_{1}$ & $\beta_{0}+\beta_{1}+\beta_{2}+\beta_{3}$ & $\beta_{2}+\beta_{3}$ \\
\hline $\begin{array}{c}\text { Control } \\
\left(D_{i}=0\right)\end{array}$ & $\beta_{0}$ & $\beta_{0}+\beta_{2}$ & $\beta_{2}$ \\
\hline Difference & $\beta_{1}$ & $\beta_{1}+\beta_{3}$ & $\beta_{3}$ \\
\hline
\end{tabular}

Source: Author's representation. 
changes in the outcome variable are caused by the event. ${ }^{9)}$

Political conflict is usually regarded as an exogenous event for firms or consumers. It is thus plausible to argue that the exogeneity assumption holds. In contrast, whether the common trend assumption holds or not depends upon the outcome variable. It is thus important to check whether the common trend assumption holds before applying a DID design.

One of the advantages of the use of a DID design is that it is relatively easy to implement. In contrast, a challenge is that one needs to find plausibly exogenous policy shocks. Moreover, even when one can find some exogenous policy shocks, the outcome variables need to satisfy the common trend assumption. While quantitative trade models focus on aggregate output, DID studies are more likely to focus on outcomes at a disaggregated level such as sectoral prices and employment. The following section explains which events the previous studies focused on and the nature of their results.

\section{Findings}

In this section, we briefly review the findings of recent studies. Based on the discussion in the previous section, we first summarize the findings of the studies based on quantitative trade models. We then review the results of the studies based on a DID design. Finally, we review some studies that employed other methodologies. Note that some studies employ different methodologies simultaneously to check the robustness of their results. ${ }^{10)}$ In this paper, we focus on their main empirical analysis.

\subsection{Quantitative trade models}

\subsubsection{Brexit}

Among the various protectionism movements, the effect of Brexit is an important concern for the global economy because it is the first case of a country's exit from the EU. Accordingly, several studies have examined its impact. Table 2 summarizes the results of six studies. Although these studies analyzed the effect of Brexit, they utilized different data and different models. However, it is interesting to note that all but Head and Mayer (2019) employed general equilibrium models. This shows a focus on general equilibrium effects.

Among five general equilibrium studies, that by Dhingra, Hwang, Ottaviano, Pessoa, Sampson, and Van Reenen (2017) is based on Eaton and Kortum's (2002) model, while Jafari and Britz (2020) used the GTAP model. Hosoe (2018), Steinberg (2019), and Latorre, Olekseyuk, and Yonezawa (2020) developed their own models to incorporate aspects such as firm heterogeneity or dynamics. The results vary across studies. Because each study focused on different outcomes, it is not easy to compare their results directly. Nonetheless, one interesting finding is that the estimated impact of Brexit on UK per capita income ranges from 1.3 percent to 2.7 percent in Dhingra et al. (2002), and around 2.29 percent in Jafari and Britz (2020). These results suggest that the negative effects of Brexit on the UK per capita income range

9) One way to test the common trend assumption is to investigate whether the group-specific trend is common or not. See, for example, Wing, Simon, and Bello-Gomez (2018).

10) For example, Heilmann (2016) employed the synthetic control method (to be explained below) as well as a DID design. Born, Müller, Schularick, and Seldláček (2019) employed a synthetic control method as well as a structural time-series analysis. 


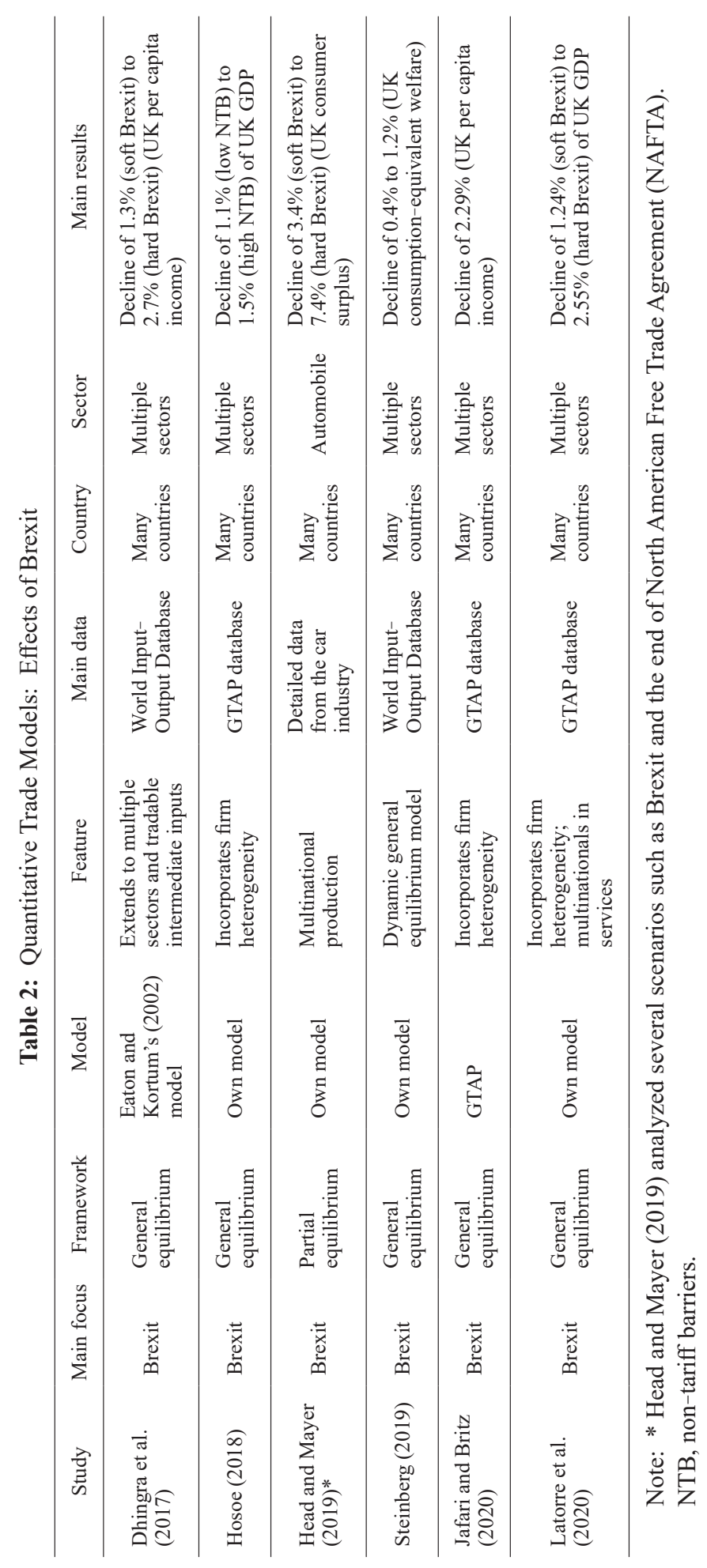


between 1.0 and 3.0 percent.

\subsubsection{US trade policies}

Another important issue is the effect of recent US trade policy. As mentioned above, the Trump administration withdrew from TPP negotiations in 2017 and enacted several waves of tariff increases in 2018. We review six studies that examined the effects of such US trade policies, as summarized in Table 3.

Among the six studies, two studies (Head and Mayer, 2019; Steinberg, 2020) examined the effects of the NAFTA termination, while the other four studies (Guo, Lu, Sheng, and Yu, 2018; Amiti et al., 2019; Fajgelbaum, Goldberg, Kennedy, and Khandelwal, 2020; Li, Balistreri, and Zhang, 2020) examined the effects of the implementation of tariffs by the US during the Trump administration. As in the studies on the effects of Brexit, these studies vary in terms of the policy being examined, models, and outcome variables. For example, two studies (Head and Mayer, 2019; Amiti et al., 2019) are based on partial equilibrium models, whereas the other four studies are based on general equilibrium models. Guo et al. (2018) and Li et al. (2020) employed Eaton and Kortum's (2002) model and the GTAP model, respectively, while the other four studies developed their own models.

Among these studies, Amiti et al. (2019) and Fajgelbaum et al. (2020) focused mainly on the impacts of the US tariffs in 2018 on US real income. Amiti et al. (2019) found that increases in the US tariffs led to losses of 8.2 billion dollars in US real income, using a partial equilibrium model. It is interesting to note that Fajgelbaum et al. (2020) also found a similar negative impact, using a general equilibrium model. They estimated losses of 7.2 billion dollars in US real income. Although a detailed investigation would be needed to explain why Fajgelbaum et al.'s (2020) general equilibrium model generated smaller negative effects than Amiti et al.'s (2019) partial equilibrium model, we can conclude that the negative effects of the US tariffs are between seven and nine billion dollars.

\subsection{DID design}

\subsubsection{Brexit and US trade policies}

We found four DID studies that focused on Brexit (Fernandes and Winters, 2021), US trade policies (Amiti, Redding, and Weinstein, 2020; Flaaen, Hortaçsu, and Tintelnot, 2021), and retaliation to the US tariffs (Fetzer and Schwarz, 2020). ${ }^{11)}$ Table 4 summarizes these studies. Fernandes and Winters (2021) examined the effects of the Brexit referendum on export volumes, prices, entry, and exit. Using the Portuguese international trade customs data from July 2014 to July 2017, the study found that exporters reduced export volumes and export prices in the UK market after the referendum shock. The study also found that the referendum shock deterred export entry to the UK market and reduced the probability of continuing to export in the UK.

For the studies on US trade policies, both studies examined the effects of US tariffs in 2018-19. Amiti et al. (2020) examined how import prices or values changed after a tariff is imposed at the product and country levels. Their results indicate that the responses to the tariffs vary across products. In most sectors, the US tariffs have been completely passed on to US

11) Fetzer (2019) employed a DID design to examine the causes rather than the effects of Brexit. 


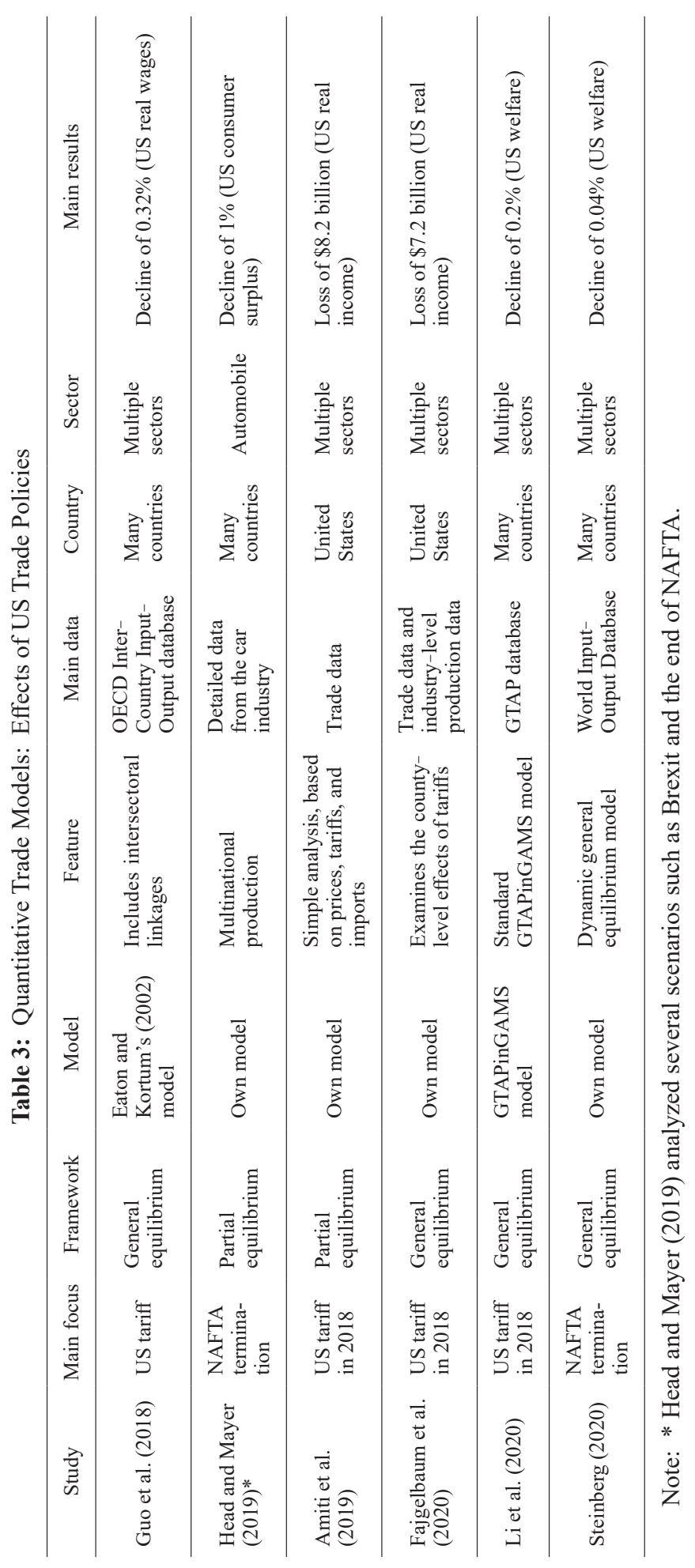




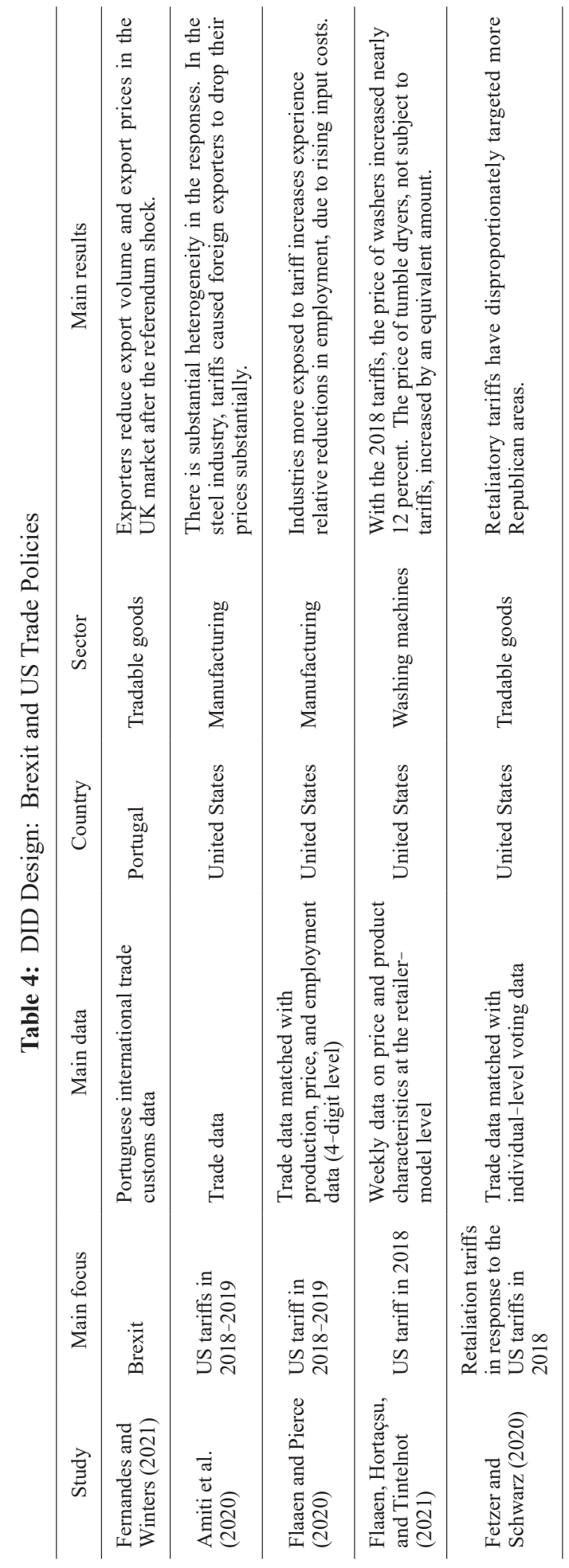


firms and consumers. However, in the steel industry, US tariffs have caused foreign exporters to substantially reduce their prices in the US market. ${ }^{12)}$ Flaaen and Pierce (2020) focused on the same event and examined the effects of US tariffs on production, employment, and prices. They found that industries more exposed to tariff increases experienced relative reductions in employment because of the increases in input costs. Flaaen, Hortaçsu, and Tintelnot (2020) examined the effects of the US tariff on the price of washing machines. Using detailed high frequency microdata from retail stores, they found that the price of these machines increased nearly 12 percent with the 2018 tariffs. They also found that the price of tumble dryers, which are not subject to tariffs, increased by an equivalent amount.

In this connection, Fetzer and Schwarz (2020) investigated the impacts of retaliation tariffs in response to the US tariffs in 2018. Matching the trade data with individual-level voting data in the United States, they found that retaliatory tariffs have disproportionately targeted more Republican areas. These studies suggest that a DID design is also a useful approach in analyzing the effects of trade policies.

\subsubsection{Consumer boycott}

Political conflict often leads to calls for a consumer boycott directed at a trade partner. A consumer boycott on imported products can be interpreted as another form of import restriction. Therefore, it may have significantly negative effects on bilateral trade. In addition, its effects can be immediate and therefore harder to evade. Furthermore, its effects may be more unpredictable than trade policy effects. This is because the popularity and longevity of the boycott are more uncertain. These features of consumer boycotts make them unique outcomes of political conflict and deserving of research attention.

A DID design is often used in analyzing the effects of consumer boycotts. ${ }^{13)}$ One reason for this is that the exogeneity of the event is plausible for consumer boycotts, although no consensus has been reached yet regarding whether they are really exogenous or not. Another reason is that, unlike tariffs, it is difficult to measure the magnitude of consumer boycotts. This makes it difficult for quantitative models to analyze their effects.

Table 5 presents a summary of the findings of the six studies. Among these six countries, Clerides, Davis, and Michis (2015), Pandya and Venkatesan (2016), and Luo and Zhou (2020) examined the impacts on sales such as soft drinks and cars. In contrast, Heilmann (2016, 2019) and Ahn, Greaney, and Kiyota (2021) examined the impacts on trade. These countries generally experienced significantly negative effects, suggesting the nonnegligible impacts of consumer boycotts.

Most of these studies implicitly assumed that the impacts were homogeneous across regions within a boycotted country or did not explicitly consider heterogeneous impacts across regions. Note that some studies such as Topalova (2007) found that the effect of trade liberal-

12) Several studies examined the effects of recent US trade policies on US domestic prices, based on alternative estimation methods. See, for example, Cavallo, Gopinath, Neiman, and Tang (2021) for the case of retail prices (based on a simple ordinary least squares).

13) An earlier example is a study by Chavis and Leslie (2009) that examined the effects of the US consumer boycott on French wine, based on a DID design. There are some studies that employ a different approach. For example, Teo, Hong, and Weich (1999) studied the effects of the South African boycott on financial markets, based on event studies (to be explained below). Ashenfelter, Ciccarella, and Shatz (2007) examined the same issue as Chavis and Leslie (2009), based on simple ordinary least squares. 


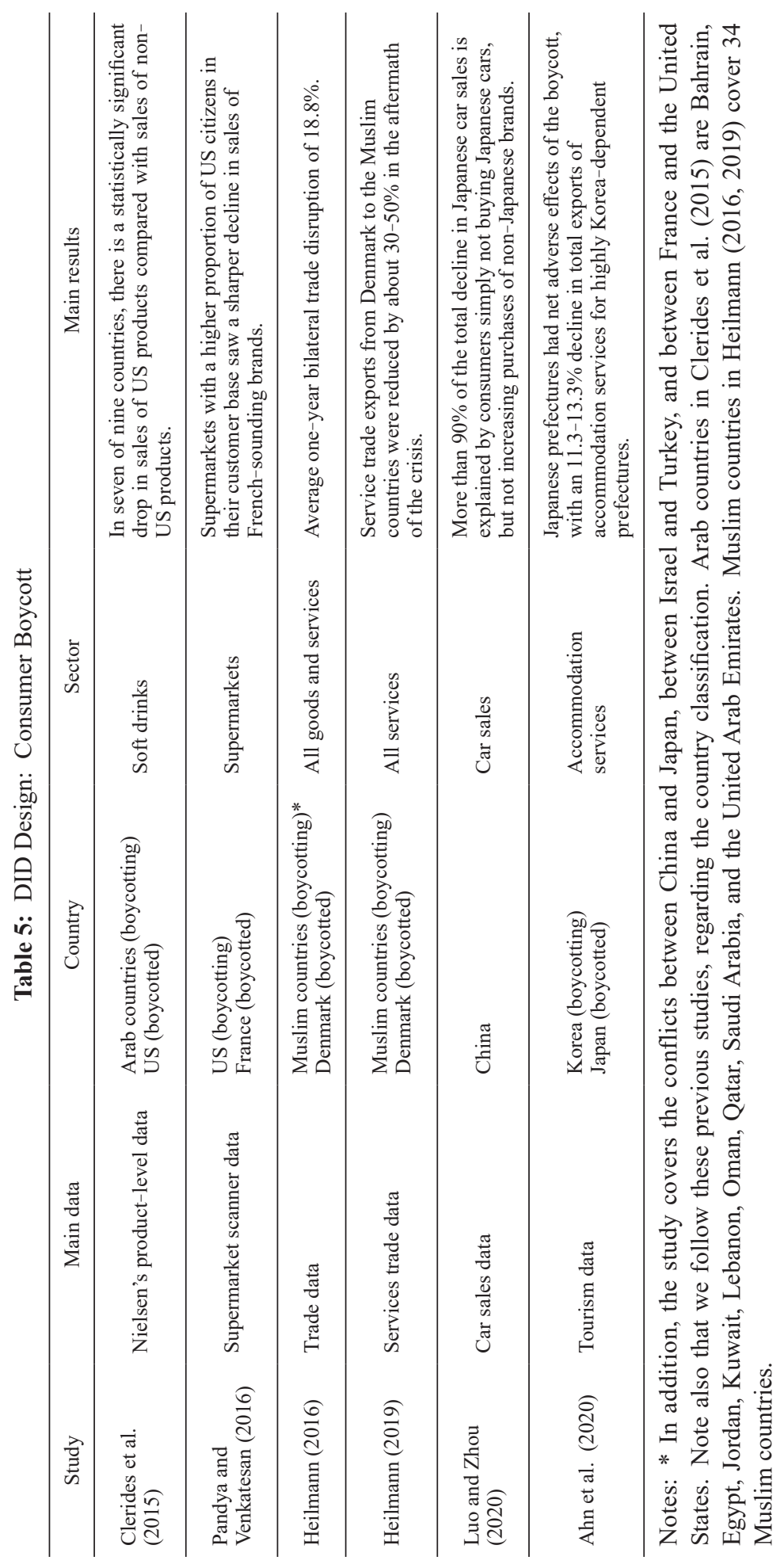


ization was heterogeneous across regions within a country. Therefore, the impact of a consumer boycott could also be heterogeneous across regions within a boycotted country.

Ahn et al. (2021) is, to our knowledge, the first study that focused on the heterogeneous effects of consumer boycotts across regions within a country. This study examined the regional impacts of bilateral boycott activity by investigating the 2019 Korean consumer boycott of travel to Japan. Employing triple- and double-differences designs, this study found that the impact of the boycott was large and regionally heterogeneous. Japanese prefectures with high (i.e., 75th percentile) preboycott dependency on visitors from Korea suffered bilateral export losses of 57 to 61 percent and aggregate export losses of 11.3 to 13.3 percent. Prefectures with low (i.e., 25th percentile) Korea dependency experienced bilateral losses of 48 to 50 percent and aggregate losses of 3.6 to 4.2 percent. The findings of Ahn et al. (2021) suggest the importance of the differential effects of consumer boycotts across regions within a country.

\subsection{Alternative approaches}

Thus far, we have focused on studies that employ quantitative trade models or DID designs. However, more recent studies employ alternative approaches that extend DID designs. One of the most popular approaches is the synthetic control method, which was developed by Abadie and Gardeazabal (2003). Another popular approach is event study. The event study approach is often used in the financial economics literature, in which a single posttreatment dummy captures the effect of the event. Like DID designs, both of these approaches mainly focus on disaggregated variables such as investment and stock returns, although some studies focused on aggregate variables such as output. This section briefly reviews these studies.

\subsubsection{Synthetic control method}

Even though a DID design is a simple and useful approach, it is based on a common trend assumption. This means that time has the same effect on the treatment and control groups. The synthetic control method is an approach that relaxes this assumption. It combines elements from matching and DID designs. While a DID design estimates the effect of an intervention by averaging over the control group, the synthetic control method tries to offer a more systematic way to assign weights to the control group. ${ }^{14)}$ More specifically, weights are estimated from the data such that the control group mirrors the treatment group as closely as possible.

Born, Müller, Schularick, and Seldláček (2019) examined the effect of Brexit on UK output, employing the synthetic control method. They found that Brexit caused a UK output loss of 1.7 to 2.5 percent by year-end 2018. In contrast, Breinlich, Leromain, Novy, and Sampson (2020) examined the effect of Brexit on UK foreign direct investment. Using the synthetic control method, they estimated that by March 2019, Brexit had led to a 17 percent increase in the number of UK outward investment transactions to the remaining 27 EU member countries. The results of these studies suggest that UK firms have been setting up European subsidiaries to retain access to the UK market after Brexit.

14) For a discussion of the difference between a DID design and the synthetic control method, see Abadie and Cattaneo (2018). 
As mentioned above, one of the advantages of the synthetic control method is that it does not rely on a common trend assumption, unlike a DID design. However, it is not necessarily clear whether the synthetic control method can be applied directly to the case when treatment is continuous or when we extend to triple differences (i.e., difference-in-difference-in-differences design). Although the synthetic control method may be another useful approach to investigate the effect of political conflicts, further discussion is warranted in a complex setting.

\subsubsection{Event studies}

Some studies have used the event study framework, focusing mainly on stock returns. ${ }^{15)}$ Schiereck, Kiesel, and Kolaric (2016) examined stock and market reactions around Brexit (on June 23, 2016) and the Lehman Brothers bankruptcy (on September 15, 2008). Conducting an event study on bank share prices, they found that the short-run fall in stock prices following the announcement of Brexit was more pronounced than that following the Lehman bankruptcy, especially for EU banks. Ramiah, Pham, and Moosa (2017) also found that the banking and travel and leisure sectors experienced significant negative effects from Brexit, focusing on the British stock market.

Davies and Studnicka (2018) focused on stock returns for the largest firms on the London Stock Exchange (FTSE 350). Using an event study, they found that the negative effects of Brexit on stock returns were heterogeneous across firms. They also found that such heterogeneity can be explained by firms' global value chains. Firms heavily exposed to the EU and UK and reliant on imported intermediates performed worse. Their study indicates which firms are anticipated to be hit hardest by Brexit, and thus the workers they employ and the regions in which they operate.

Amiti, Kong, and Weinstein (2020) examined the effects of China-US tariff announcements on the stock returns and investment of US firms. Their results indicated that the tariff actions in 2018 and 2019 will lower the investment growth of the listed US firms by 1.9 percentage points by the end of 2020. They also found that most of the reduction in the US market value of these firms comes from US tariff announcements, not from Chinese retaliation announcements. Similarly to Davies and Studnicka (2018), Huang, Lin, Liu, and Tang (2018) further examined the relationship with firm characteristics. They found that US firms depending more on exports and imports from China experienced larger declines in market value.

These event studies also complement the analysis of the quantitative trade models and DID designs. Notice, however, that while the framework of event studies is simple, recent studies introduce leads and lags into DID designs, paying much more attention to heterogeneity over time. This allows us to check whether the degree to which the post-treatment effects were dynamic and whether the two groups were comparable in terms of outcome dynamics during the pre-treatment period (Cunningham, 2021).

\subsection{Are the impacts of political conflict long-lived?}

Thus far, we have found significant impacts of Brexit, recent US trade policies, and recent political conflicts. One may ask whether such impacts are long-lived. Because we focus on

15) A study by Fisman, Hamao, and Wang (2014) also examined the effects of the China-Japan relationship in 2005 and 2010 on stock returns, based on an event study. 
the recent events, it is difficult to answer this question directly. Nonetheless, some studies have attempted to answer it, and have focused on different events. We review some of them below.

Fuchs and Klann (2013) asked whether countries that receive the Dalai Lama despite China's opposition experience a significant reduction in their exports to China. Their results indicate that countries officially receiving the Dalai Lama at the highest political level are punished through a decline in their exports to China. However, this negative effect disappears in the second year after a meeting took place.

Du, Ju, Ramirez, and Yao (2017) examined the effects of political conflict on bilateral trade between China and its major trading partners. Estimating a gravity model, they found that political shocks are short-lived. An earlier study by Chavis and Leslie (2009) found significantly negative effects of the US consumer boycott on French wine. However, such effects were short-lived. In sum, the previous studies indicated that significantly negative effects of political conflict did not continue for a long term.

\section{Concluding Remarks}

In light of the growing concerns about increasing protectionism, this paper reviewed recent empirical studies that have investigated the effects of protection. We showed that these studies mainly employed either quantitative trade models or difference-in-differences (DID) designs to address the issue of trade protectionism.

While quantitative trade models are suited to counterfactual analysis, the models are sometimes complex. Moreover, recent trade models have fewer structural parameters to generate plausible results that can be replicated easily by other researchers. Although it may not be easy to build such models, the development of new quantitative trade models would be a significant contribution to the literature and policy discussions.

In contrast, a DID design is relatively easy to implement. However, it relies on the assumption that both the treatment and control groups follow the same trend. If this assumption does not hold, it is difficult to identify the causal relationship. There remain several important questions for further research, such as the sectoral and regional differences of the effects of political conflicts. An application of these approaches to other political conflicts could also help us to investigate the applicability of these methods.

In addition to these approaches, more recent studies employ alternative approaches such as synthetic control methods and event studies. These studies are relatively new, and further developments are therefore expected. The application of these approaches depends on the research question and data availability. These approaches thus complement each other. The appropriate choice of approach will enable researchers to address the research issue correctly, which contributes to the literature and policy discussions.

Note that the number of studies on political conflicts is increasing rapidly. Some recent studies used detailed product-level data and attempted to identify the effects of protectionist trade policies on domestic prices. To identify the policy impacts on the domestic economy in a precise manner, it is imperative that the quality and coverage of the data must be improved and expanded. 
Impacts of Protectionism and Political Conflict: Recent Developments

\section{References}

Abadie, A. and J. Gardeazabal (2003), The Economic Costs of Conflict: A Case Study of the Basque Country, American Economic Review, 93: 113-132.

Abadie, A. and M.D. Cattaneo (2018), Econometric Methods for Program Evaluation, Annual Review of Economics, 10: 465-503.

Adao, R., A. Costinot, and D. Donaldson (2017), Nonparametric Counterfactual Predictions in Neoclassical Models of International Trade, American Economic Review, 107: 633-689.

Ahn, J., T. Greaney, and K. Kiyota (2021), Political Conflict and Angry Consumers: Evaluating the Regional Impacts of a Consumer Boycott on Trade in Services, Keio University and University of Hawai'i, Manuscript.

Alabrese, E., S.O. Becker, T. Fetzer, and D. Novy (2019), Who Voted for Brexit? Individual and Regional Data Combined, European Journal of Political Economy, 56: 132-150.

Amiti, M., S.H. Kong, and D.E. Weinstein (2020), The Effect of the U.S.-China Trade War on U.S. Investment, National Bureau of Economic Research (NBER) Working Paper, No. 27114.

Amiti, M., S.J. Redding, and D.E. Weinstein (2019), The Impact of the 2018 Tariffs on Prices and Welfare, Journal of Economic Perspectives, 33: 187-210.

Amiti, M., S.J. Redding, and D.E. Weinstein (2020), Who's Paying for the US Tariffs? A Longer-Term Perspective, American Economic Review, 110: 541-546.

Ashenfelter, O., S. Ciccarella, and H.J. Shatz (2007), French Wine and the U.S. Boycott of 2003: Does Politics Really Affect Commerce? Journal of Wine Economics, 2: 55-74.

Baier, S.L., J.H. Bergstrand, and J. Bruno (2019), Putting Canada in the Penalty Box: Trade and Welfare Effects of Eliminating North American Free Trade Agreement, The World Economy, 42: 3488-3514.

Becker, S.O., T. Fetzer, and D. Novy (2017), Who Voted for Brexit: A Comprehensive District-Level Analysis, Economic Policy, 32: 601-651.

Breinlich, H., E. Leromain, D. Novy, and T. Sampson (2020), Voting with Their Money: Brexit and Outward Investment by UK Firms, European Economic Review, 124: 103400.

Born, B., G.J. Müller, M. Schularick, and P. Seldláček (2019), The Costs of Economic Nationalism: Evidence from the Brexit Experiment, Economic Journal, 129: 2722-2744.

Cavallo, A., G. Gopinath, B. Neiman, and J. Tang (2021), Tariff Passthrough at the Border and at the Store: Evidence from US Trade Policy, American Economic Review: Insights, 3: 19-34.

Chavis, L. and P. Leslie (2009), Consumer Boycotts: The Impacts of the Iraq War on French Wine Sales in the U.S., Quantitative Marketing Economics, 7: 37-67.

Clerides, S., P. Davis, and A. Michis (2015), National Sentiment and Consumer Choice: The Iraq War and Sales of US Products in Arab Countries, Scandinavian Journal of Economics, 117: 829-851.

Costinot, A. and A. Rodríguez-Clare (2014), Trade Theory with Numbers: Quantifying the Consequences of Globalization, in G. Gopinath, E. Helpman, and K. Rogoff (eds.), Handbook of International Economics, Volume 4, 197-261, Amsterdam: Elsevier.

Cunningham, S. (2021), Causal Inference: The Mixtape, New Haven, CT: Yale University Press.

Davies, R.B. and Z. Studnicka (2018), The Heterogenous Impact of Brexit: Early Indications from the FTSE, European Economic Review, 110: 1-17.

Davis, C.L. and S. Meunier (2011), Business as Usual? Economic Responses to Political Tensions, American Journal of Political Science, 55: 628-646.

Dhingra, S., H. Huang, G. Ottaviano, J.P. Pessoa, T. Sampson, and J. Van Reenen (2017), Trade after Brexit, Economic Policy, 32: 651-705.

Di Tella, R. and D. Rodrik (2020), Labour Market Shocks and the Demand for Trade Protection: Evidence from Online Surveys, Economic Journal, 130: 1008-1030.

Du, Y., J. Ju, C.D. Ramirez, and X. Yao (2017), Bilateral Trade and Shocks in Political Relations: Evidence from China and Some of its Major Trading Partners, 1990-2013, Journal of International Economics, 
108: 211-225.

Eaton, J. and S. Kortum (2002), Technology, Geography, and Trade, Econometrica, 70: 1741-1779.

Evenett, S., M. Fiorini, J. Fritz, B. Hoeckman, P. Lukaszuk, N. Rocha, M. Ruta, F. Santi, and A. Shingal (2020), Trade Policy Responses to the COVID-19 Pandemic Crisis: Evidence from a New Data Set, World Bank Policy Research Working Paper, No. 9498.

Fajgelbaum, P.D., P.K. Goldberg, P.J. Kennedy, and A.K. Khandelwal (2020), The Return to Protectionism, Quarterly Journal of Economics, 135: 1-55.

Fajgelbaum, P.D. and A.K. Khandelwal (2021), The Economic Impacts of the US-China Trade War, National Bureau of Economic Research (NBER) Working Paper, No. 29315.

Fernandes, A.P. and L.A. Winters (2021), Exporters and Shocks: The Impact of the Brexit Vote Shock on Bilateral Exports to the UK, Journal of International Economics, 131: 103489.

Fetzer, T. (2019), Did Austerity Cause Brexit? American Economic Review, 109: 3849-3886.

Fetzer, T. and C. Schwarz (2020), Tariffs and Politics: Evidence from Trump's Trade Wars, Economic Journal, 131: 1-25.

Fisman, R., Y. Hamao, and Y. Wang (2014), Nationalism and Economic Exchange: Evidence from Shocks to Sino-Japanese Relations, Review of Financial Studies, 27: 2626-2660.

Flaaen, A.B., A. Hortaçsu, and F. Tintelnot (2020), The Production Relocation and Price Effects of U.S. Trade Policy: The Case of Washing Machines, American Economic Review, 110: 2103-2127.

Flaaen, A. and J. Pierce (2020), Disentangling the Effects of the 2018-2019 Tariffs on a Globally Connected U.S. Manufacturing Sector, Federal Reserve Board, Manuscript.

Fuchs, A. and N.-H. Klann (2013), Paying a Visit: The Dalai Lama Effect on International Trade, Journal of International Economics, 91: 164-177.

Fuchs, A., L. Kaplan, K. Kis-Katos, S.S. Schmidt, F. Turbanisch, and F. Wang (2020), Mask Wars: China’s Exports of Medical Goods in Times of COVID-19, University of Gottingen, Center for European, Governance and Economic Development Research Discussion Papers, No. 398.

Guo, M., L. Lu, L. Sheng, and M. Yu (2018), The Day After Tomorrow: Evaluating the Burden of Trump's Trade War, Asian Economic Papers, 17: 101-120.

Hufbauer, G.C. and K.A. Elliott (1994), Measuring the Costs of Protection in the United States, Washington. D.C.: Institute for International Economics.

Haidar, J.I. (2017), Sanctions and Export Deflection: Evidence from Iran, Economic Policy, 32: 319-355.

Head, K. and T. Mayer (2019), Brands in Motion: How Frictions Shape Multinational Production, American Economic Review, 109: 3073-3124.

Heilmann, K. (2016), Does Political Conflict Hurt Trade? Evidence from Consumer Boycotts, Journal of International Economics, 99: 171-191.

Heilmann, K. (2019), Political Conflict and Service Trade, in T. Besedeš and V. Nitsch (eds.), Disrupted Economic Relationships: Disasters, Sanctions, Dissolutions, Cambridge, MA: MIT Press.

Hertel, T.W. (ed.) (1997), Global Trade Analysis: Modeling and Applications, Cambridge, UK: Cambridge University Press.

Hertel, T.W., R.A. McDougall, B.G. Narayanan, and A.H. Aguiar (2012), Behavioral Parameters, in B.G. Narayanan, A.H. Aguiar, and R.A. McDougall (eds.) Global Trade, Assistance, and Production: The GTAP 8 Data Base, West Lafayette, IN: Purdue University Center for Global Trade Analysis.

Hosoe, N. (2018), Impact of Border Barriers, Returning Migrants, and Trade Diversion in Brexit: Firm Exit and Loss of Variety, Economic Modeling, 69: 193-204.

Huang, Y., C. Lin, S. Liu, and H. Tang (2018), Trade Network and Firm Value: Evidence from the U.S.China Trade War, Available at SSRN: https://ssrn.com/abstract=3227972.

Jafari, Y. and W. Britz (2020), Brexit: An Economy-Wide Impact of Assessment on Trade, Immigration, and Foreign Direct Investment, Empirica, 47: 17-52.

Kehoe, T.J., P.S. Pujolàs, and J. Rossbach (2017), Quantitative Trade Models: Developments and Challenges, Annual Review of Economics, 9: 295-325. 
Latorre, M.C., Z. Olekseyuk, and H. Yonezawa (2020), Foreign Multinationals in Service Sectors: A General Equilibrium Analysis of Brexit, The World Economy, 43: 2830-2859.

Li, M., E.J. Balistreri, and W. Zhang (2020), The U.S.-China Trade War: Tariff Data and General Equilibrium Analysis, Journal of Asian Economics, 69: 101216.

Li, Y., Z. Jian, W. Tian, and L. Zhao (2021), How Political Conflict Distort Bilateral Trade: Firm-level Evidence from China, Journal of Economic Behavior and Organization, 183: 233-249.

Liberini, F., A.J. Oswald, E. Proto, and M. Redoano (2019), Was Brexit Triggered by the Old and Unhappy? Or by Financial Feelings? Journal of Economic Behavior and Organization, 161: 287-302.

Luo, Z. and Y. Zhou (2020), Decomposing the Effects of Consumer Boycotts: Evidence from the Anti-Japanese Demonstration in China, Empirical Economics, 58: 2615-2634.

Michaels, G. and X. Zhi (2010), Freedom Fries, American Economic Journal: Applied Economics, 2: 256281.

Ossa, R. (2016), Quantitative Models of Commercial Policy, in K. Bagwell and R.W. Staiger (eds.) Handbook of Commercial Policy, Volume 1A, Amsterdam, Netherlands: North-Holland, 207-259.

Pandya, S.S. and R. Venkatesan (2016), French Roast: Consumer Response to International Conflict - Evidence from Supermarket Scanner Data, Review of Economics and Statistics, 98: 42-56.

Ramiah, V., H.N.A. Pham, and I. Moosa (2017), The Sectoral Effects of Brexit on the British Economy: Early Evidence from the Reaction of the Stock Market, Applied Economics, 49: 25082514.

Rodrik, D. (2018), What Do Trade Agreements Really Do? Journal of Economic Perspectives, 32: 73-90.

Sazanami, Y., S. Urata, and H. Kawai (1995), Measuring the Costs of Protection in Japan, Washington, D.C.: Institute for International Economics.

Schiereck, D., F. Kiesel, and S. Kolaric (2016), Brexit: (Not) Another Lehman Moment for Banks, Financial Research Letters, 19: 291-297.

Steinberg, J.B. (2019), Brexit and the Macroeconomic Impact of Trade Policy Uncertainty, Journal of International Economics, 117: 175-95.

Steinberg, J.B. (2020), The Macroeconomic Impact of NAFTA Termination, Canadian Journal of Economics, 53: 821-865.

Tanaka, A., B. Ito, and R. Wakasugi (2019), How Do Exporters Respond to Exogenous Shocks: Evidence from Japanese Firm-level Data, Japan and the World Economy, 51: 100962.

Teoh, S.H., I. Welch, and C.P. Wazzan (1999), The Effect of Socially Activist Investment Policies on the Financial Markets: Evidence from the South African Boycott, Journal of Business, 72: 35-89.

Topalova, P. (2010), Factor Immobility and Regional Impacts of Trade Liberalization: Evidence on Poverty from India, American Economic Journal: Applied Economics, 2: 1-41.

Wing, C., K. Simon, and R.A. Bello-Gomez (2018), Designing Difference in Differences Studies: Best Practices for Public Health Policy Research, Annual Review of Public Health, 39: 453-469. 